\title{
REFLECTIONS ON APPENDICITIS IN A MILITARY ENVIRONMENT
}

\author{
Lieutenant-Colonel R. D. H. PARKER, M.B., F.R.C.S.I., R.A.M.C. \\ Military Hospital, Colchester
}

IN surveying some of the more common causes of emergency reference to the surgical department the label 'Abdominal Pain-query Appendicitis' occurs frequently.

While typical the picture of appendicitis is well known and not usually in doubt, unfortunately it is present in only about 50 per cent of cases. In the remainder, modified by pecularities in the position of the appendix, the age, sex and type of patient and for other more obscure reasons, the picture is blurred and the diagnosis may be missed.

This is of some importance to us in the Army. If a soldier has his appendix removed at the right time it should be possible to discharge him from hospital in about a week, and after a period of sick leave, return him to duty within three weeks.

If his appendix is not removed until some degree of local or general peritonitis has developed this period may be doubled, trebled or quadrupled due to one complication or another. For instance, operating on a patient with infected free fluid in the abdomen, even if you avoid any serious complication such as a pelvic or subphrenic abscess, you are very likely to get a degree of wound infection which may delay discharge considerably.

The question of wound infection in appendicitis, after due regard has been paid to the question of ward and theatre aseptic precautions depends to a large extent in the final analysis on the conditions present at the operation-the degree of peritoneal contamination and the skill of the operator in removing an infected appendix without contaminating tissue planes, preventing haematoma formation and his judgement in the use of drainage. The principal factors leading to perforation and peritoneal contamination are delay in diagnosis both before and after admission and delay in reporting sick. At this hospital, in the past two years out of 131 operations for appendicitis there were 13 cases of wound infection, an infection rate of 9.9 per cent.

The relationship between the state of the appendix, peritoneal contamination, the type of organism and the time in hospital is indicated in Table I.

Irrigation of the wound at operation with tetracycline solution in cases with peritoneal contamination has recently been recommended as preferable to insufflation with Polymixin, Bacitracin and Neomycin powder. A reduction of infection rate from 18 per cent to 2 per cent is claimed (Longland et at 1971).

It should not be forgotten that there is still an appreciable mortality from appendicitis, from 3 to 5 per cent in any large series according to Shephard (1968). However in the Army in the three years to 1970 of 1928 operations for appendicitis on Army personnel there were only two deaths connected with appendicitis-both were primarily anaesthetic deaths and neither occurred in a Military Hospital (A.M.D. Stats).

It is proposed to discuss briefly some variations in the appendicular picture with particular reference to five types of patients encountered in military practice - children, the fat soldier, young women, the elderly and patients in medical wards. 
Table I

Relationship between the state of the appendix, peritoneal contamination, the type of organism and the time in hospital

\begin{tabular}{|c|c|c|c|c|c|}
\hline Case & $\begin{array}{l}\text { State of } \\
\text { appendix }\end{array}$ & $\begin{array}{c}\text { Peritoneal } \\
\text { contamination }\end{array}$ & Organism & $\begin{array}{l}\text { Days in } \\
\text { hospital }\end{array}$ & Comments \\
\hline 1 & Perforated & $++t$ & B. coli & 38 & Pelvic abscess \\
\hline 2 & Perforated & ++ & B. coli & 25 & \\
\hline 3 & Perforated & +++ & B. coli & 28 & \\
\hline 4 & Perforated & ++ & B. coli & 17 & \\
\hline 5 & Perforated & ++ & B. coli & 35 & \\
\hline 6 & $\begin{array}{l}\text { Gangrenous, } \\
\text { non-perforated }\end{array}$ & $+t$ & Sterile & 14 & \\
\hline 7 & $\begin{array}{l}\text { Acute, } \\
\text { non-perforated }\end{array}$ & + & S. pyogenes & 10 & \\
\hline 8 & $\begin{array}{l}\text { Follicular } \\
\text { hyperplasia }\end{array}$ & Nil & S. pyogenes & 33 & Wound haematoma \\
\hline 9 & $\begin{array}{l}\text { Retrocaecal } \\
\text { gangrenous }\end{array}$ & ++ & $\begin{array}{l}\text { B. coli } \\
\text { Proteous }\end{array}$ & 134 & Obese, faecal fistula \\
\hline 12 & $\begin{array}{l}\text { Acute, } \\
\text { non-perforated }\end{array}$ & + & S. pyogenes & 15 & \\
\hline 11 & $\begin{array}{l}\text { Acute, } \\
\text { non-perforated } \\
\text { retrocaecal }\end{array}$ & + & Sterile & 39 & Wound haemotoma \\
\hline 12 & $\begin{array}{l}\text { Acute, } \\
\text { non-perforated }\end{array}$ & + & S. pyogenes & 15 & \\
\hline 13 & $\begin{array}{l}\text { Gangrenous, } \\
\text { perforated }\end{array}$ & ++ & $\begin{array}{l}\text { B. coli } \\
\text { Pseudomonas }\end{array}$ & 31 & \\
\hline
\end{tabular}

Notes: +++ denotes severe, ++ moderate and + slight.

One or two general observations can be made initially.

Temperature. Classically this is slightly raised, but it is important to remember that a normal temperature does not exclude appendicitis or indicate a mild catarrhal or resolving attack as many imagine. A great many distended, obstructed, gangrenous and free-lying appendices on the point of rupture have been removed in the presence of a normal temperature. A high temperature of over $101^{\circ}$ in the first day or two, in the adult, is rather against appendicitis. Later, however, with the onset of peritonitis the temperature may well be high. In children on the other hand, a high temperature in the early stages is not unusual.

White blood count. This again is often unreliable and a normal count can be obtained in the presence of a gangrenous appendix. However, a high W.B.C. with increase in polymorphs in association with suggestive symptoms and signs is useful confirmatory evidence.

The history and signs should be viewed as a whole and equated with the probable course and duration of the condition. Sometimes one may be more valuable than the 
other. For example, local tenderness anywhere in the right lower abdomen is one of the more constant signs but with a retrocaecal appendix and a fat abdomen a false impression of the degree of tenderness may be obtained. The usual force elicits no response and deep firmer palpation is required before the characteristic appendicular wince is obtained. I use the expression 'appendicular wince '-a spasmodic raising of the right side of the mouth and closure of the right eye-with deliberation. I have never seen an expression quite like it in any other form of abdominal pain.

Again, an appendix mass does not usually form under 4 to 5 days and is usually a contra-indication to operation, But, sometimes, in a thin abdomen, a mass can be felt early, within two days. This is due to omentum wrapping itself round the inflamed appendix tip and lying against the anterior abdominal wall. The appendix is still eminently suitable for removal at this stage. It is suggested that the time to remove an acute appendix is when it is diagnosed-whether it be $1,2,3$ or 4 days after the onset of symptoms. I do not think there is any place for saying 'its a mild appendix and will probably settle'. The only contra-indication to operation is an appendix mass and even this may be deceptive. For example, in a fat abdomen it may only be possible to feel a mass under anaesthetic-in such circumstances, after reviewing the history, particularly the duration of symptoms, it may be wise to call off the operation even after the patient has been anaesthetised.

The five different types of patient mentioned will now be considered and some pitfalls in each type mentioned.

\section{Children}

Appendicitis is said to be rare before the age of 2 years. I have seen it at six months and it has been described in the first few days of life. The normal defence mechanisms to a septic focus in the abdomen are poorly developed in young children. The appendix is relatively thin walled and the omentum is small, fragile and contains little fat. The condition accordingly progresses more rapidly and is more likely to cause general peritonitis than localise. In these very young patients, a parent, preferably the mother (fathers usually are not much use) must be available for the history. Once she has given it, she must not be allowed to interrupt further or distract the child from the examiner who must try to almost hypnotise the child into giving him its full attention. The examiner should be seated and comfortable and the approach must be gradual and gentle. Any haste, sharpness or roughness results in a struggling, tense, tearful child and a decision becomes impossible. The importance of re-examination, particularly in distinguishing the 'fluctuating symptoms of acute mesenteric adenitis has been recently stressed' (Leading article 1970).

Simple observation goes a long way in the diagnosis, for example, an abdomen which is distended or does not move on respiration, a flexed right hip, a dirty tongue or foetor! A child with appendicitis is unlikely to be hungry. He may well be very thirsty however. It should not be forgotten that at times the condition may be preceded by or occur during the course of an URTI, tonsillitis, measles or an enteric infection. It should also be noted that in view of the ease which dehydration can be produced in a vomiting small child a fair amount of resuscitation is sometimes required before the operation. 


\section{Fat Soldiers}

This type of case includes the congenitally fat soldier, the heavily built, well muscled, weight lifting, hammer throwing 'tough' types and those who are just heavy eaters and drinkers. The type is often noted in Senior N.C.O's and here the condition could be labelled the 'Sergeant's Appendix '. These individuals often have a high pain threshold, may be plethoric and taciturn and are often reluctant to admit to anything. They have often carried on with their duties for a day or two with determination, in spite of pain before reporting sick.

The signs are masked by a thick abdominal wall, a fat omentum and an appendix more often than not retrocaecal.

Accordingly, more than usual pressure in palpation is required to elicit tenderness and this may be confined to an area along the iliac crest towards the loin. Rigidity likewise is rather difficult to gauge in these rather solid abdomens and masses are not easily felt. Again it seems that this is the type of patient where one often finds a normal temperature, pulse and white cell count.

Finally this type of case is notoriously difficult to operate on and should never be left to a junior.

Case History. A sergeant, aged 32 years, was admitted with typical appendicitis of twenty-four hours duration. He was seen by a competent House Surgeon and after discussion with a senior by telephone was told to go ahead. He did not mention that the patient was extremely obese and the senior neglected to ask. After struggling manfully for an hour through an inadequate incision he called for assistance when it was found he was trying to take out part of the ileum. A very difficult retrocaecal gangrenous appendix was removed. The convalescence was stormy with wound abscess, recurrent subacute obstruction and finally the development of a faecal fistula which delayed discharge for four months.

\section{Young women}

In the age group 17 to 25 , young women are frequently admitted to hospital with acute pain in the R.I.F. and frequently have their appendices removed for this. Acute appendicitis, however, seems to me to be relatively infrequent in this type of patient and more often than not the cause turns out to be a small haemoperitoneum from a small ovarian cyst. One knows of course about 'Mittelschmerz' but it seems to me that these small cysts can cause trouble at any time during the cycle.

The pain and tenderness are often quite severe and although one suspects the cause and anticipates that it will probably settle, one cannot be certain. The abdomen is opened, a normal appendix removed, a small haemoperitoneum sucked out and a small bleeding cyst excised or oversewn. This type of problem is sometimes found in young Q.A.R.A.N.C. nurses. Gynaecological advise is of course obtained but at times the problem is recurrent and even a medical discharge may have to be considered.

One other variation in women is perhaps worth mentioning. Tenderness in the fornices and on moving the cervix is often held to be strong evidence of salpingitis or parametritis and it usually is. However, a pelvic appendix hanging in the Pouch of Douglas against the back of the uterus will give much the same picture. 


\section{The elderly}

We do not have many patients in the 60 to 70 plus age group in the Army. But now and then a soldier's visiting parents or some elderly entitled civilian does come under our care.

Appendicitis in the elderly can be particularly insidious and lethal. The pain threshold is again high and they may be inaccurate and rambling historians, reluctant to admit to more than a slight pain in the side for 2 to 3 days which is often dismissed as indigestion they have had many times before. Indeed, the initial symptoms may be slight up to the stage of perforation when they may collapse with acute pain and vomiting. When operation is undertaken soon after a general peritonitis is already present.

Ileus, residual abscess, respiratory, vascular, and urinary complications all contribute to the significantly higher mortality in this age group.

\section{The appendix in medical wards}

Every now and then an acute appendix is admitted to the medical wards usually in the guise of gastro-enteritis. This assumes particular significance during epidemics of enteritis and dysentery especially in tropical areas where most epidemics yield a quota of one or two acute appendices hidden in a ward full of acute diarrhoea. Recognition in these cases depends totally on the Physician's awareness of the possibility as the Surgeon is unlikely to see these cases initially.

In conclusion, it should be stressed that the variations, combinations and permutations of symptoms and signs in the clinical presentation of the appendicular picture is almost infinite. I have touched only very briefly on some of the more common variations but the only way to avoid unnecessary morbidity and even tragedy is to constantly remember the possibility of appendicitis in any presentation of abdominal pain.

\section{Acknowledgement}

I am grateful to A.M.D. (Stats.) for providing statistics on Appendicitis in the Army.

\section{REFERENCES}

LEADING ARTICle (1970). Brit. med. J. iii, 599.

Longland, C. J., Gray, J. G., Lees, W. and Garrett, J. A. M. (1971). Brit. J. Surg. $58,117$.

Pledger, H. G. and Buchan, R. (1969). Brit. med. J. iv, 466.

ShEPHERD, J. A. (1968). The Acute Abdomen. E. \& S. Livingstone. Edinburgh. 